\title{
Article \\ An Ultra-Wideband Vivaldi Antenna System for Long-Distance Electromagnetic Detection
}

\author{
Jinjing Ren ${ }^{1}$, Hezhihan Fan ${ }^{1}$, Qi Tang ${ }^{2}$, Zhongyuan Yu ${ }^{1}$, Yang Xiao ${ }^{1}$ and Xiang Zhou ${ }^{1, *}$ \\ 1 Research Center for Electromagnetic Environment Effects, Southeast University, Nanjing 211189, China; \\ renjj@seu.edu.cn (J.R.); 220190348@seu.edu.cn (H.F.); 213172530@seu.edu.cn (Z.Y.); \\ xiaoyang66@seu.edu.cn (Y.X.) \\ 2 Science and Technology on Near-Surface Detection Laboratory, Wuxi 214035, China; tangqiwx@163.com \\ * Correspondence: zhouxiang@seu.edu.cn
}

Citation: Ren, J.; Fan, H.; Tang, Q.; Yu, Z.; Xiao, Y.; Zhou, X. An Ultra-Wideband Vivaldi Antenna System for Long-Distance Electromagnetic Detection. Appl. Sci. 2022, 12, 528. https://doi.org/ 10.3390/app12010528

Academic Editor:

Girdhari Chaudhary

Received: 22 November 2021

Accepted: 2 January 2022

Published: 5 January 2022

Publisher's Note: MDPI stays neutral with regard to jurisdictional claims in published maps and institutional affiliations.

Copyright: (C) 2022 by the authors. Licensee MDPI, Basel, Switzerland. This article is an open access article distributed under the terms and conditions of the Creative Commons Attribution (CC BY) license (https:// creativecommons.org/licenses/by/ $4.0 /)$.

\begin{abstract}
Enlarging or reducing the antenna beam width of antennas can improve the positioning capability of detection systems. A miniaturized and easily fabricated ultra-wideband (UWB) antenna system for long-distance electromagnetic detection is proposed in this article. Two ultra-wideband Vivaldi antennae were designed. One was the transmitting antenna with a beam width of $90^{\circ}$ or above, the other was a narrow beam antenna array with beam width less than $10^{\circ}$, as a receiving antenna. Both proposed antennae feature broadside gain diagrams with stable radiation patterns and wideband impedance matching in the frequency range between $2.5 \mathrm{GHz}$ and $4 \mathrm{GHz}$. After detecting their frequency and time-domain behaviors, the detection system can achieve measurements covering a radius of $30 \mathrm{~m}$.
\end{abstract}

Keywords: Vivaldi antennas; wideband antennas; electromagnetic detection

\section{Introduction}

Ultrawideband (UWB) antennas have been increasingly applied in wireless communication, biomedical detection, and radar systems in recent years [1-6]. As a tapered slot antenna, the Vivaldi antenna is well-known for its high gain, directive radiation pattern, planar structure and fairly wide bandwidth [7], and it is one of the best options for the UWB technology $[8,9]$. Its small transverse spacing makes it a good candidate for antenna arrays [10]. The Vivaldi antenna can be classified into the category of end fire traveling wave antennas, has theoretically infinite bandwidth [11], and can be used to form an ultrawideband antenna system [12]. However, the Vivaldi antenna requires a large antenna size to achieve excellent performance in the low-end working band $[13,14]$. The width of a Vivaldi antenna should reach at least one half-wavelength so as to achieve effective radiation, according to the research work in [15].

In order to reduce the size of the Vivaldi antenna and to further optimize it, some scholars have put forward many new strategies. To be specific, in [8], the feeding part is improved to realize miniaturization. The antenna in [8] aims to increase the area of feeding part and adopt feed with stepped structure. In [16,17], radiation parts are improved. The antenna in [16] is seen to open unequal semicircle slots, while that in [17] can be witnessed to open multiple rectangular slots on the edge of the radiation part, which helps improve antenna gain. The antenna in [18] reflects the method of increasing the length of the dielectric substrate to improve the directivity, and the antenna in [19] has an enhanced gain over whole frequency band by adding an additional structure that supports spoof surface plasmon polaritons (SSPP) as the parasitic element. When compared with several antennae, the antennae in $[8,20]$ perform better with miniaturization, but their performance with regard to the direction and gain is far from scholars' satisfaction. The antennae in [16-19] have higher antenna gain, while they cannot meet scholars' expectations in miniaturization. 
This article designed a set of receiving and transmitting antennas based on Vivaldi antennae, and built a long-distance electromagnetic detection system. In the target detection test, the transmitting antenna is used as illumination feed, and the receiving antenna obtains the signal reflected by the target from scanning angle to find the target and the azimuth angle. Then, with the Time Domain Transmissometer (TDT) measurement results, the target position is judged.

The working frequency band of the detection system is $2.5 \sim 4 \mathrm{GHz}$. According to the working principle of the detection system, the beamwidth of the transmitting antenna needs to cover a wide angle to ensure that the target under test can receive and reflect the signal radiated by the transmitting antenna. Therefore, the half-power beamwidth (HPBW) of the transmitting antenna should be larger than $90^{\circ}$. Correspondingly, in order to quickly and accurately determine the azimuth angle and judge the position of the target, the beamwidth of the receiving antenna is required to be as narrow as possible and have good directivity. Therefore, the receiving antenna should be a typical one that has narrow HPBW and good directional performance and that should also be miniaturized. To achieve long-distance detection, the target detection system should have a high transmitting power, and the antennae should be characterized by boasting better impedance matching and higher gain performance [21].

\section{Antenna Configuration Design and Performance}

\subsection{Ultra-Wideband Wide Beam Antenna}

In general, the bandwidth of a traditional Vivaldi antenna is determined by the transition from the feeding microstrip line to the slot line and the dimensions of the antenna. For the planar slit gradient antenna, the spacing of the narrow end of the slot line opening determines the highest working frequency, while the spacing of the wide end determines the lowest working frequency [22]. Considering that the working frequency range is $2.5 \sim 4 \mathrm{GHz}$, the end width of the slot line can be set as $50 \mathrm{~mm}$ and the starting end width can be set as $2 \mathrm{~mm}$. Since the radiation of the antenna is generated by the current extending along the gradient slots on both sides [23], widening the width of the antenna will make the current flow through a longer path and generate a wider main beam. However, it also affects the impedance of the antenna. By further optimized simulation, the width of the antenna's metal sheet can be obtained.

Figure 1 shows the configuration of the proposed transmitting antenna. The antenna is fabricated on a $150 \times 150 \times 1.6 \mathrm{~mm}$ FR4 substrate with a dielectric constant of 4.3 . The structure of the Vivaldi antenna is composed by dielectric substrate, metal ground plane, and feeding microstrip transmission line. The exponential tapered slot, which is on the ground plane, can be expressed as:

$$
\begin{aligned}
& y=C_{1} e^{a x}+C_{2} \\
& C_{1}=\frac{y_{2}-y_{1}}{e^{a x_{2}}-e^{a x_{1}}} \\
& C_{1}=\frac{y_{2}-y_{1}}{e^{a x_{2}}-e^{a x_{1}}}
\end{aligned}
$$

where $\left(x_{1}, y_{1}\right),\left(x_{2}, y_{2}\right)$ are the peak and bottom point, respectively, of the exponential tapered shape and $a$ is the exponential factor of the antenna. The optimized dimensions of the proposed antenna are tabulated in Table 1. 


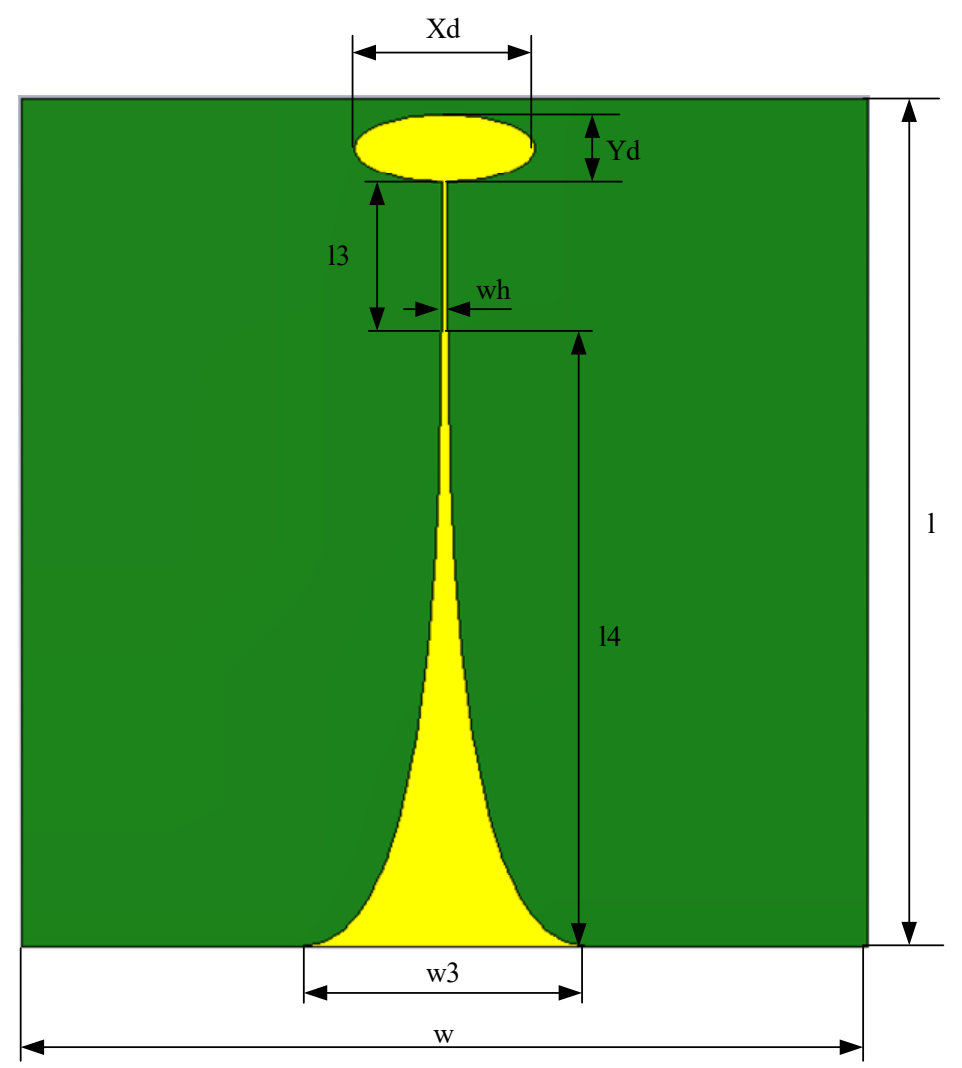

Figure 1. Structure of the transmitting antenna.

Table 1. Transmitting Antenna parameters (mm).

\begin{tabular}{cc}
\hline Parameter & Value \\
\hline Xd & 32.0 \\
Yd & 12.0 \\
13 & 22.8 \\
wh & 1.0 \\
14 & 112.5 \\
w3 & 48.0 \\
w & 150.0 \\
l & 150.0 \\
\hline
\end{tabular}

$\mathrm{Xd}$ and Yd are the short axis and long axis of the elliptical resonator cavity, respectively. The values 13 and wh are the length and width of the rectangular transitional slot, respectively. The value 14 is the length of the gradient slot, while w3 is the widest width of the gradient slot.

After optimizing the parameters of feed line structure, the working frequency range was $1.4-8 \mathrm{GHz}$. As shown in Figure 2a, the return loss of the simulated and measured antenna was adjusted to $-10 \mathrm{~dB}$ over the frequency band from $1.4 \mathrm{GHz}$ to $8 \mathrm{GHz}$. Furthermore, the simulated and measured normalized E-plane radiation patterns of the antennae operating at different frequencies are shown in Figure 3. Higher-order modes are generated at higher frequencies, resulting in some ripples in the radiation patterns, which is observed in Figure 3. The measured and simulated beam width of the transmitting antenna with structure at different frequencies are shown in Table 2 . The antenna is a wide beam antenna and the half-power beamwidth (HPBW) can be maintained above $90^{\circ}$ in the frequency range $2.5-5 \mathrm{GHz}$, and the maximum beam width is $122^{\circ}$. What is worth mentioning is that the gain is shown in Figure $2 b$, which is greater than $3.26 \mathrm{dBi}$ and that the directivity consistency is good. 


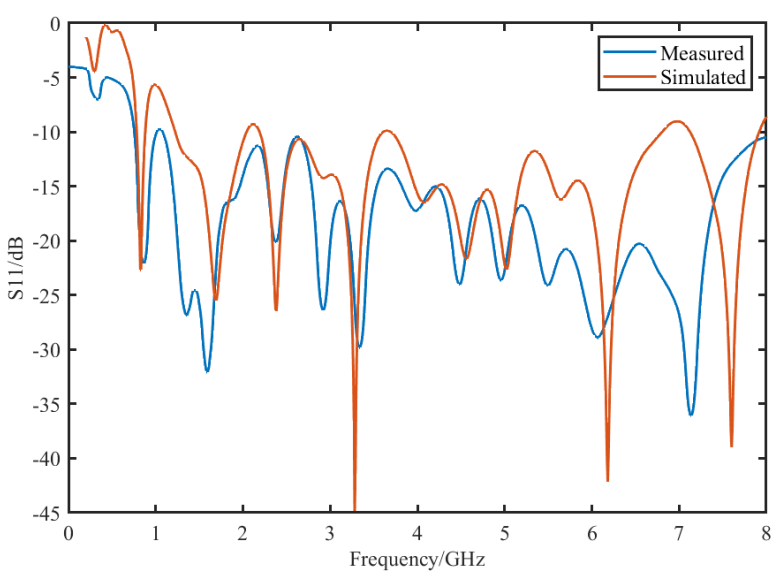

(a)

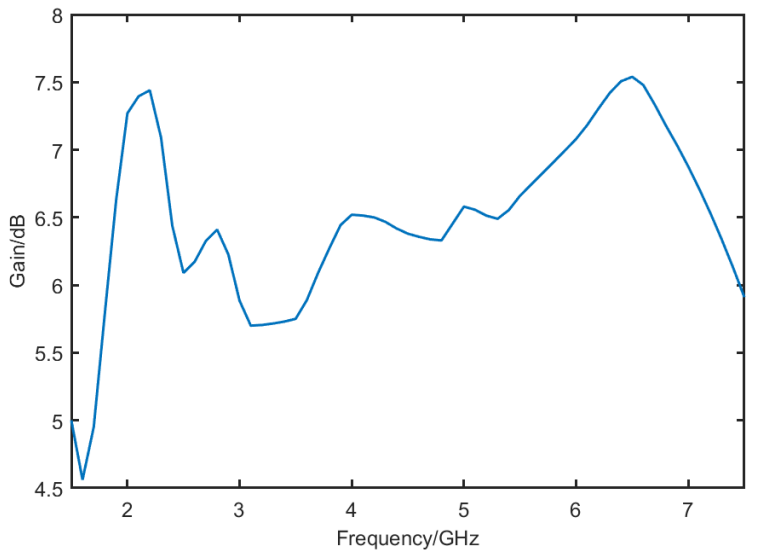

(b)

Figure 2. (a) Return loss of the measured and simulated transmitting antenna. (b) The gain of the simulated transmitting antenna.

\section{Simulated - - Measured}

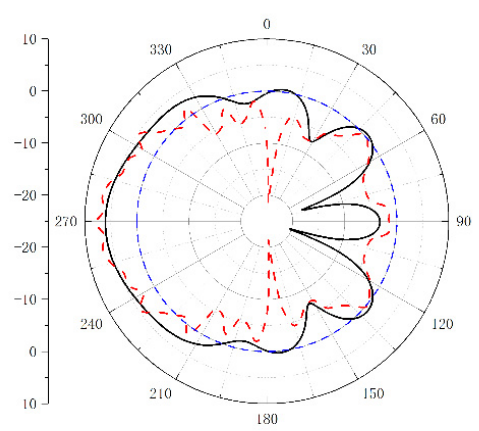

(a)

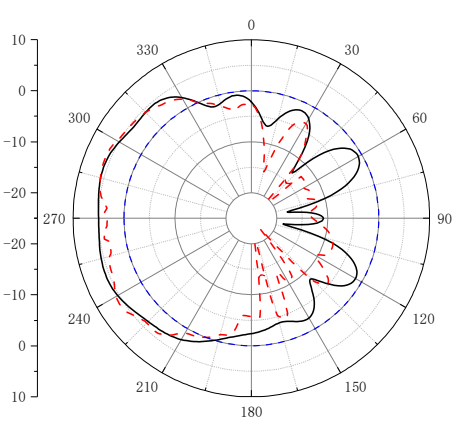

(c)

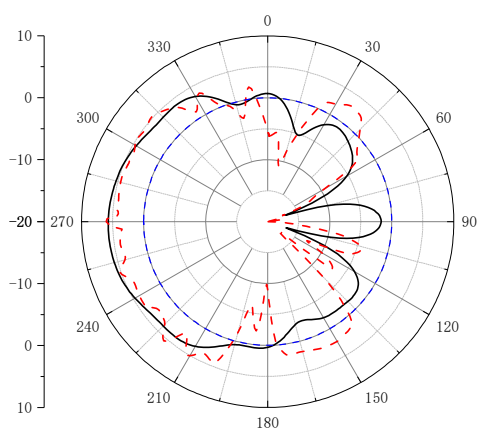

(b)

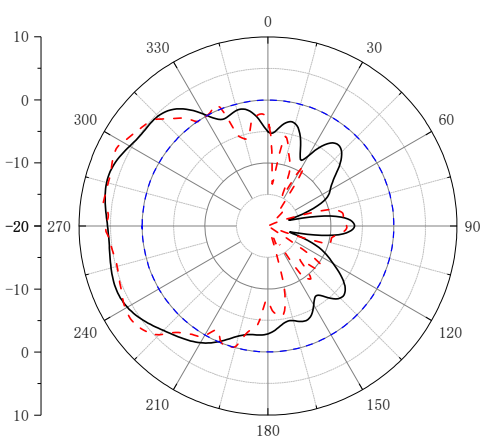

(d)

Figure 3. Cont. 


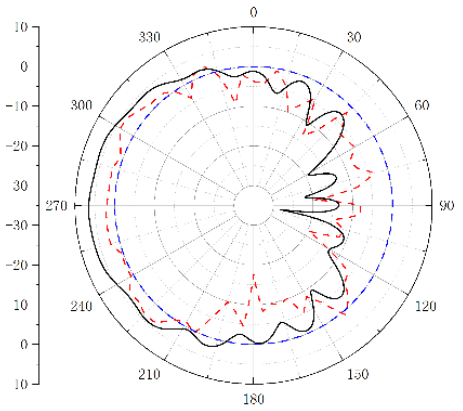

(e)

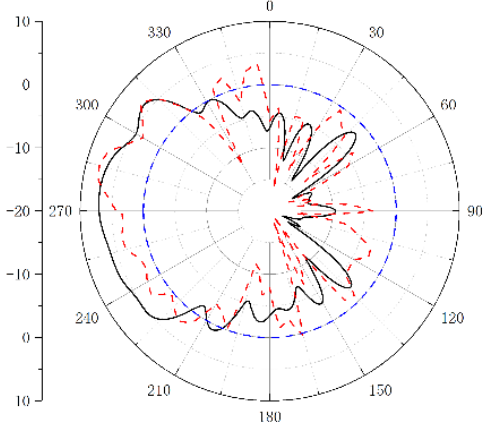

$(\mathbf{f})$

Figure 3. Simulated E-plane radiation patterns of the transmitting antenna with structure at (a) $2.5 \mathrm{GHz}$; (b) $3 \mathrm{GHz}$; (c) $3.5 \mathrm{GHz}$; and (d) $4 \mathrm{GHz}$; (e) $5 \mathrm{GHz}$; (f) $6 \mathrm{GHz}$.

Table 2. The beam width of the transmitting antenna at different frequency.

\begin{tabular}{ccc}
\hline Frequency/GHz & HPBW (Measured) $/^{\circ}$ & HPBW $\left(\right.$ Simulated) $/^{\circ}$ \\
\hline $2.5 \mathrm{GHz}$ & $108^{\circ}$ & $122.3^{\circ}$ \\
$3 \mathrm{GHz}$ & $122^{\circ}$ & $128.3^{\circ}$ \\
$3.5 \mathrm{GHz}$ & $109^{\circ}$ & $120^{\circ}$ \\
$4 \mathrm{GHz}$ & $90^{\circ}$ & $91.9^{\circ}$ \\
$5 \mathrm{GHz}$ & $95^{\circ}$ & $104.7^{\circ}$ \\
$6 \mathrm{GHz}$ & $86^{\circ}$ & $91.8^{\circ}$ \\
\hline
\end{tabular}

\subsection{Ultra-Wideband Narrow Beam Antenna}

To ensure the detection accuracy of the detection system, the receiving antenna should be featured by owing ultra-wideband, narrow beam and high gain performance. Therefore, the beam width of the antenna unit was required to be reduced.

For Vivaldi antennae, the main solutions for reducing the antenna beam width included adding a director and slotting the metal patch. It should be noted that both methods will affect the standing wave ratio of the antenna. The antenna adopting a gradual slotting method yields better results in the direction of the main beam when compared with the method of ordinary slotting, and such a method can help increase the gain of the antenna. At the same time, the triangular director of the antenna can also help increase the gain of the antenna and reduce the beam width of the antenna.

To improve radiation characteristics of the antenna, a series of symmetric slots were installed in the extremities of the antenna. The modifications are shown in Figure 4 . The modified antenna with optimized slots can secure a compact structure with improved radiation patterns and better impedance bandwidth. Each slot operates as an RLC resonator where the resonant wavelength can be estimated by the following expression:

$$
l=\frac{\lambda_{0}}{4} \sqrt{\frac{2}{1+\varepsilon_{r}}}
$$

where $l$ is the length of slot and $\varepsilon_{r}$ is dielectric constant of the substrate. 


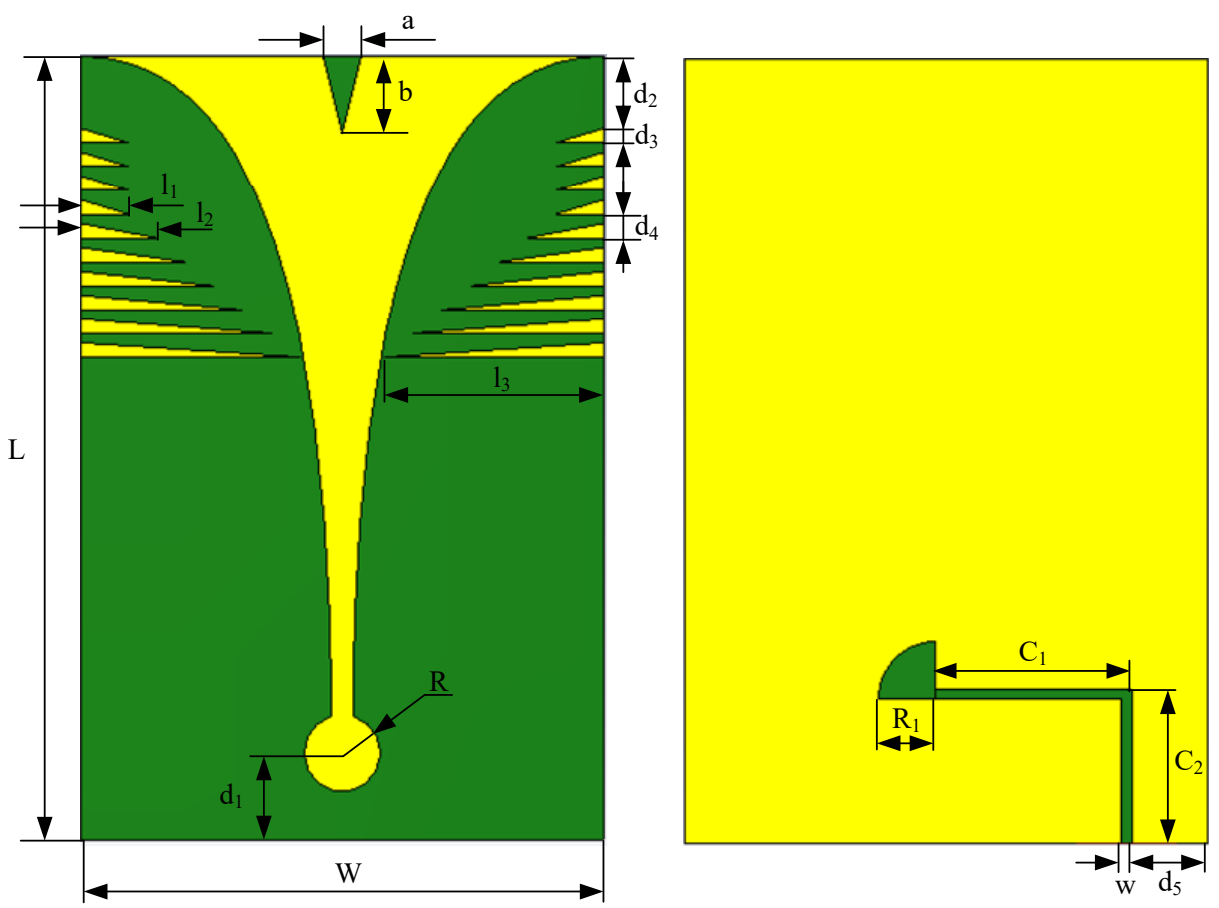

Figure 4. Vivaldi narrow-beam antenna structure (front and back).

After CST modelling and multiple simulation analysis of the parameters, the final optimized triangular slot height registered $8 \mathrm{~mm}$ and the width was recorded as $4 \mathrm{~mm}$. The length of the triangle slot adopted an arithmetic sequence, and the minimum slot height is $5 \mathrm{~m}$. The height difference between two adjacent rectangles is $3 \mathrm{~mm}$. At the same time, three additional triangular slots are opened near the wide side of the antenna, which can contribute a lot without affecting other electrical properties of the antenna. The final optimization results of the various parameters of narrow-beam antenna are shown in Table 3.

Table 3. Final optimization results of the parameters of Vivaldi narrow-beam antenna (mm).

\begin{tabular}{cccc}
\hline Parameter & Value & Parameter & Value \\
\hline W & 55 & $\mathrm{~d}_{5}$ & 8 \\
$\mathrm{~L}$ & 82 & $\mathrm{l}_{1}$ & 5 \\
$\mathrm{a}$ & 4 & $\mathrm{l}_{2}$ & 8 \\
$\mathrm{~b}$ & 8 & $\mathrm{l}_{3}$ & 23 \\
$\mathrm{R}$ & 4 & $\mathrm{R}_{1}$ & 6 \\
$\mathrm{~d}_{1}$ & 9 & $\mathrm{w}$ & 1 \\
$\mathrm{~d}_{2}$ & 7.5 & $\mathrm{C}_{1}$ & 20.6 \\
$\mathrm{~d}_{3}$ & 1.5 & $\mathrm{C}_{2}$ & 16 \\
$\mathrm{~d}_{4}$ & 2.5 & & \\
\hline
\end{tabular}

The final model of the designed ultra-wideband narrow-beam Vivaldi antenna was simulated. As shown in Figure 5a, the return loss of the simulated narrow beam Vivaldi antenna was adjusted to $-10 \mathrm{~dB}$ over the frequency band from 2.5 to $8.5 \mathrm{GHz}$. The simulated E-plane radiation pattern of the antenna at different frequencies are shown in Figure 6. In addition, the HPBW of the antenna with structures at different frequencies are shown in Table 4. It also lists out the comparison between the proposed antenna and other published related antennas. From Table 4, the proposed Vivaldi narrow-beam antenna structure was smaller in dimension than the antennae as reported in [19,24-28]. In addition, the comparative results show the improvement in maintaining an HPBW less than $70^{\circ}$ in the frequency range between 2.5 and $8 \mathrm{GHz}$. The HPBW of proposed antenna is smaller than the antennas in $[19,24,27]$, and the bandwidth is larger than the antennas in the others. 
Meanwhile, the minimum beam width is $59.4^{\circ}$. What's more, Figure $5 \mathrm{~b}$ show the gain of the proposed antenna, which is greater than $4.54 \mathrm{dBi}$ and the directivity consistency is good. According to the characteristics, the proposed antenna can be an excellent candidate for the array element of the receiving antenna in an ultra-wideband Vivaldi antenna system.

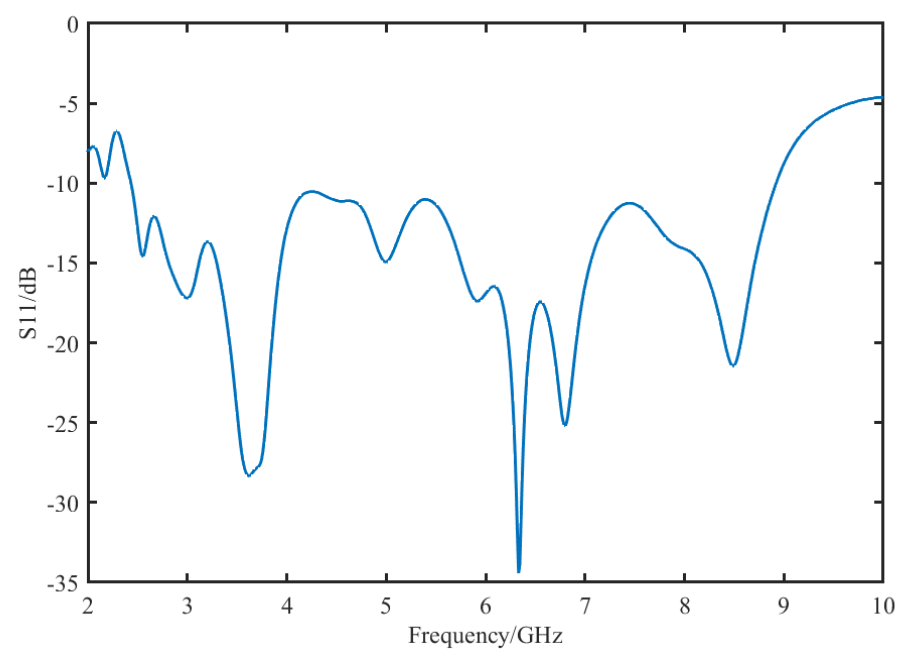

(a)

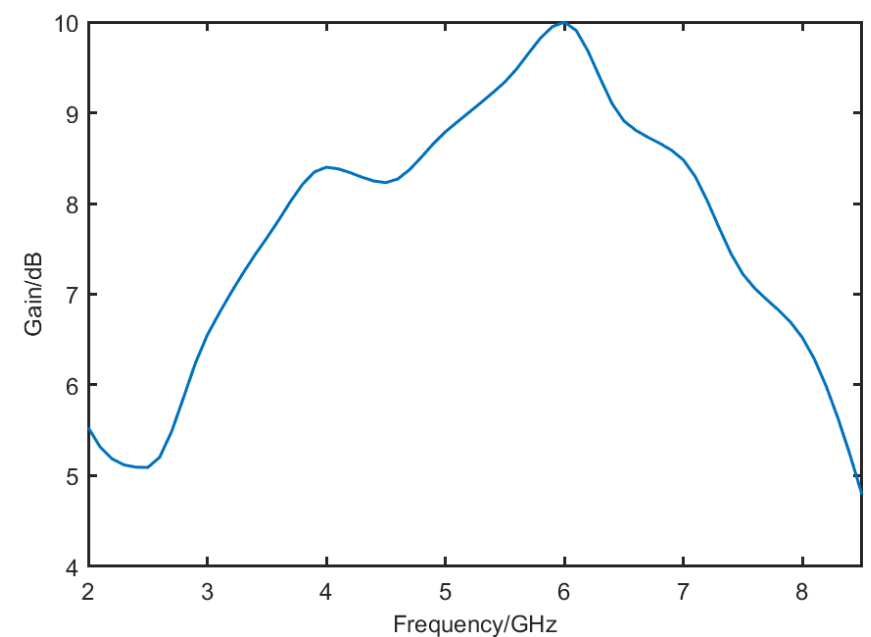

(b)

Figure 5. (a) Return loss of the simulated narrow beam Vivaldi antenna. (b) The gain of the simulated narrow beam Vivaldi antenna.

Table 4. Comparison between proposed antenna and literature.

\begin{tabular}{|c|c|c|c|c|c|c|c|c|c|}
\hline \multirow{2}{*}{ Ref. No. } & \multirow{2}{*}{$\begin{array}{l}\text { Dimension } \\
\left(\mathrm{mm}^{2}\right)\end{array}$} & \multirow{2}{*}{$\begin{array}{l}\text { Operating } \\
\text { Frequency }\end{array}$} & \multicolumn{7}{|c|}{ HPBW } \\
\hline & & & $2 \mathrm{GHz}$ & $3 \mathrm{GHz}$ & $4 \mathrm{GHz}$ & $5 \mathrm{GHz}$ & $6 \mathrm{GHz}$ & $7 \mathrm{GHz}$ & $8 \mathrm{GHz}$ \\
\hline [24] & $120 \times 90$ & $2-5 \mathrm{GHz}$ & 130 & - & 75 & 65 & - & - & - \\
\hline [19] & $200 \times 80$ & 3-14 GHz & - & $85^{\circ}$ & - & - & - & $50^{\circ}$ & - \\
\hline [25] & $297 \times 190$ & $0.6-3.2 \mathrm{GHz}$ & $51.4^{\circ}$ & $55^{\circ}$ & - & - & - & - & - \\
\hline [26] & $258 \times 150$ & $0.5-6 \mathrm{GHz}$ & $48.7^{\circ}$ & $45.1^{\circ}$ & $54.3^{\circ}$ & $71.1^{\circ}$ & $58.6^{\circ}$ & - & - \\
\hline [27] & $274 \times 282$ & $0.4-9.8 \mathrm{GHz}$ & - & $74^{\circ}$ & - & - & - & - & $74^{\circ}$ \\
\hline [28] & $100 \times 90$ & 3-6 GHz & - & $55^{\circ}$ & - & - & $55^{\circ}$ & - & - \\
\hline proposed & $82 \times 55$ & $2.5-8.5 \mathrm{GHz}$ & $65.9^{\circ}$ & $65.2^{\circ}$ & $59.4^{\circ}$ & $55.4^{\circ}$ & $44^{\circ}$ & $46.7^{\circ}$ & $66.2^{\circ}$ \\
\hline
\end{tabular}



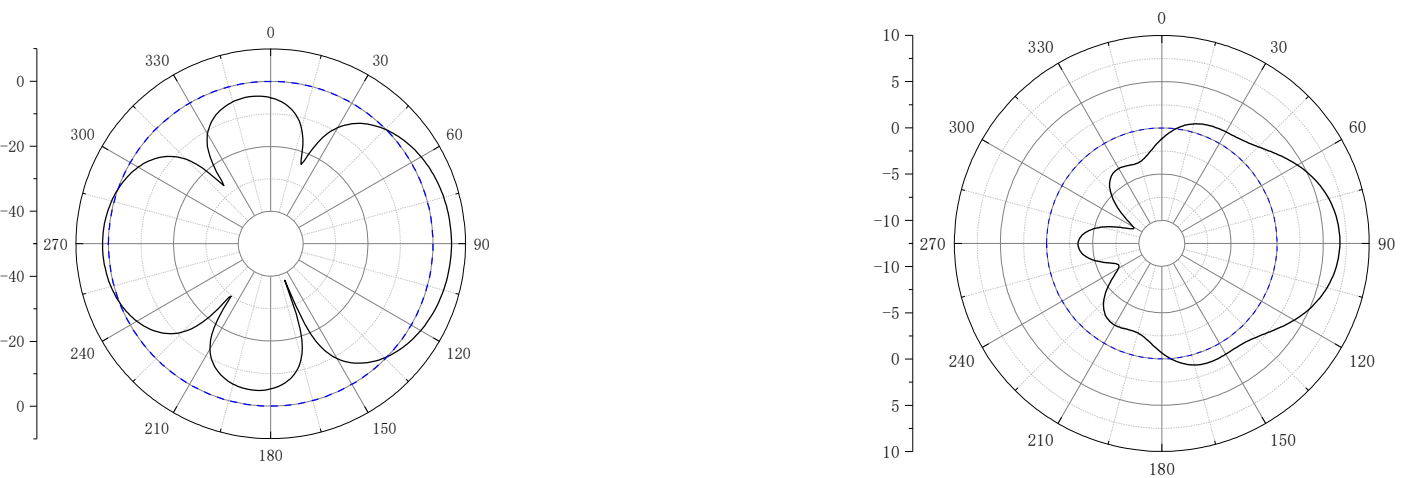

(a)

(b)
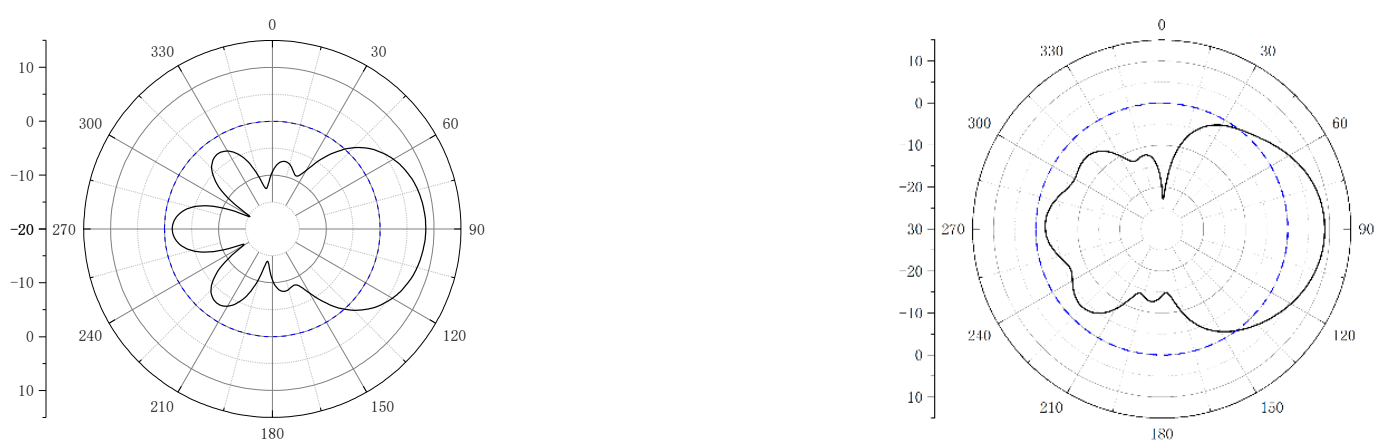

(c)

(d)
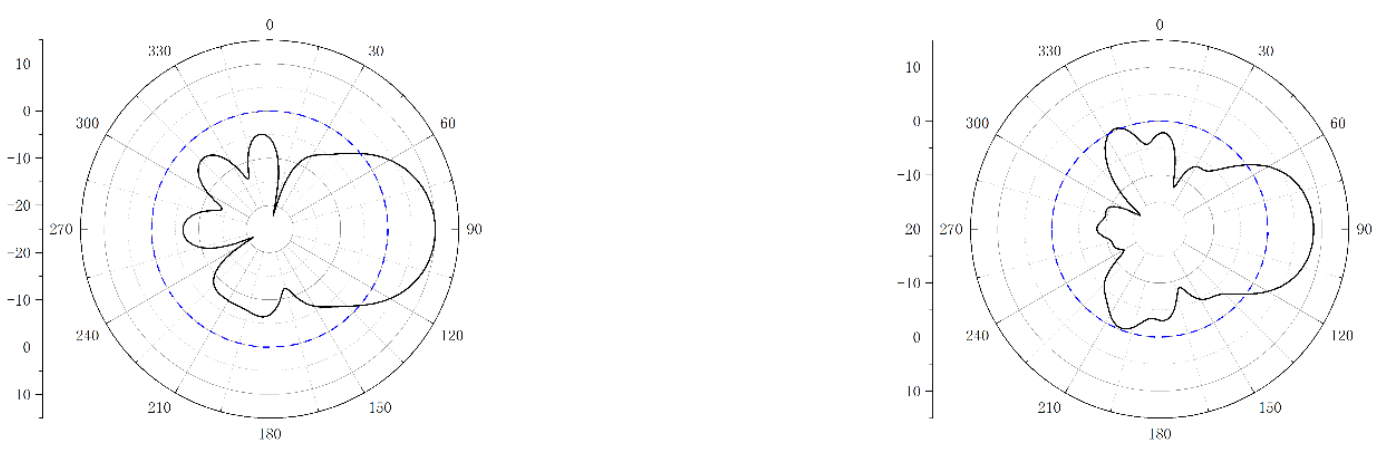

(e)

(f)

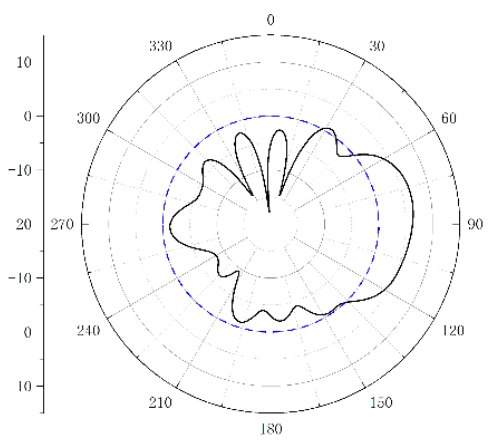

(g)

Figure 6. E-plane pattern of narrow beam Vivaldi antenna with structure at (a) $2 \mathrm{GHz}$; (b) $3 \mathrm{GHz}$; and (c) $4 \mathrm{GHz}$; (d) $5 \mathrm{GHz}$; (e) $6 \mathrm{GHz}$ (f) $7 \mathrm{GHz}$; (g) $8 \mathrm{GHz}$. 
To strengthen the directional radiation capability of the antenna and meet the requirement that the beam width has to be less than $10^{\circ}$, the Vivaldi antennae with improved beam width were arranged into an 8-element array. To reduce the feed ports, a power divider was used to feed the antenna array. The antenna array model is shown in Figure 7 and the array antenna parameters are shown in Table 5.
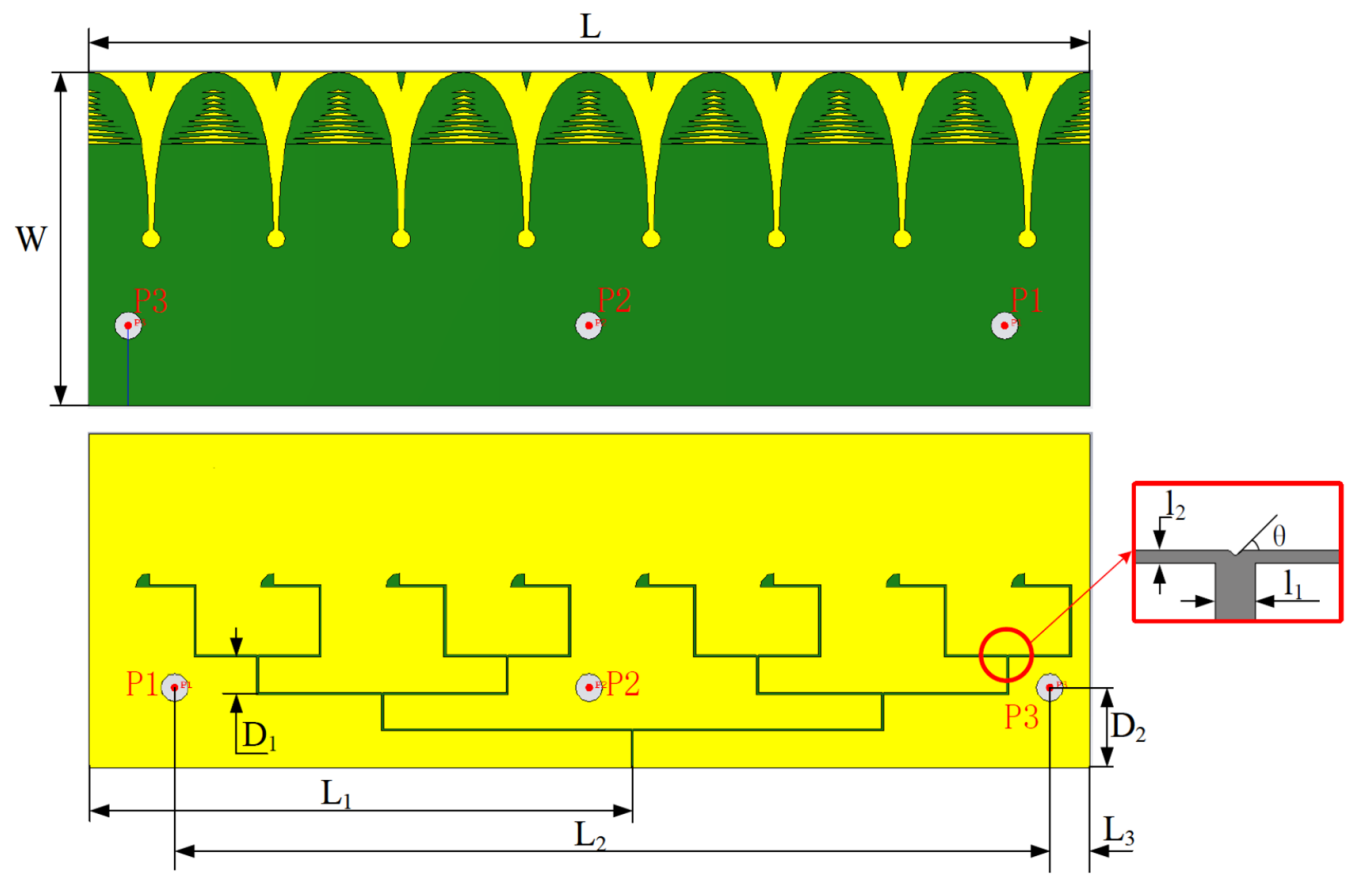

Figure 7. Model and size of 8-element Vivaldi array antenna.

Table 5. Array antenna parameters (mm).

\begin{tabular}{cc}
\hline Parameter & Value \\
\hline L & 440 \\
W & 146 \\
$D 1$ & 16 \\
$D 2$ & 35 \\
$L 1$ & 239 \\
$L 2$ & 385 \\
$L 3$ & 17.5 \\
$l 1$ & 3.2 \\
$l 2$ & 1 \\
$\theta$ & $60^{\circ}$ \\
\hline
\end{tabular}

The single element is $82 \mathrm{~mm}$ long and $55 \mathrm{~mm}$ wide. The power divider is a microstrip T-branch power divider which is enlarged in the Figure 7 . The length below the T-shaped knot is $16 \mathrm{~mm}$, which is about $\lambda / 4$, and the width is $3.2 \mathrm{~mm}$. The width on both sides is $1 \mathrm{~mm}$, and the width of the antenna unit feeder is also $1 \mathrm{~mm}$. The distance between the last-level power divider line and the leftmost side of the antenna array is $239 \mathrm{~mm}$, and the other levels of power divider are distributed in a symmetrical structure. The length of each level of power division microstrip line is $16 \mathrm{~mm}$ and the width is $1 \mathrm{~mm}$. Three positioning points were marked, and a hole with an inner diameter of $6 \mathrm{~mm}$ was drilled so that the antenna array can be assembled on the turntable support.

The final model of the designed narrow-beam eight-element antenna array was simulated and measured, and the simulated and measured E-plane radiation patterns of the antenna at different frequencies were obtained as shown in Figure 8. As shown in Figure 9a, the original Vivaldi antenna works in the frequency range from 2.5 to $4 \mathrm{GHz}$. The return 
loss is less than $-10 \mathrm{~dB}$ in the whole band, except that $3.9 \mathrm{GHz}$ is about $-9.5 \mathrm{~dB}$. The main lobe beam width at 2, 3, $4 \mathrm{GHz}$ respectively is shown in Table 6. The HPBW in the E-plane of the proposed array are shown in Table 6. The HPBW are all less than $10^{\circ}$, and the gains are greater than $10 \mathrm{dBi}$, which are shown in Figure 9b.

Table 6. Narrow beam Vivaldi 8-element array E-plane pattern main lobe width.

\begin{tabular}{ccc}
\hline Frequency/GHz & HPBW (Measured) $/^{\circ}$ & HPBW (Simulated) $/^{\circ}$ \\
\hline $2 \mathrm{GHz}$ & $9.8^{\circ}$ & $8.3^{\circ}$ \\
$3 \mathrm{GHz}$ & $7^{\circ}$ & $5.6^{\circ}$ \\
$4 \mathrm{GHz}$ & $4^{\circ}$ & $4.2^{\circ}$ \\
\hline
\end{tabular}

Phase linearity within the operational bandwidth is an important aspect of wideband antenna design. It is observed from Figure $9 \mathrm{c}$ that the group delay response of the transmitting antenna is almost flat, which indicates distortionless transmission. The maximum group delay of the receiving array antenna is within $2 \mathrm{~ns}$, which is acceptable.

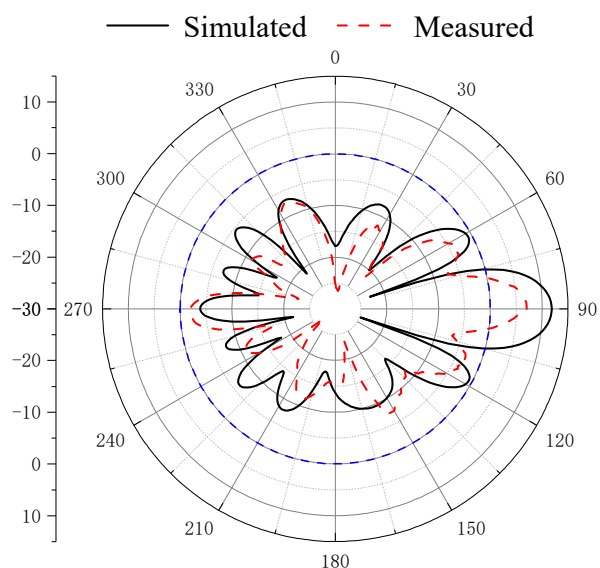

(a)

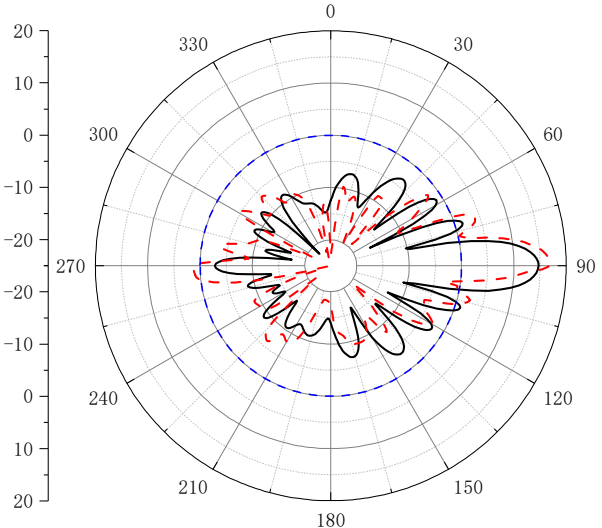

(b)

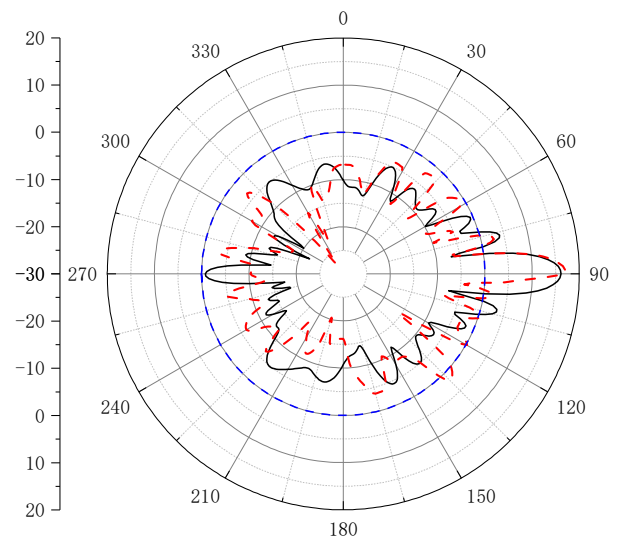

(c)

Figure 8. E-plane pattern of Vivaldi 8-element array with structure at (a) $2 \mathrm{GHz}$; (b) $3 \mathrm{GHz}$; and (c) $4 \mathrm{GHz}$. 


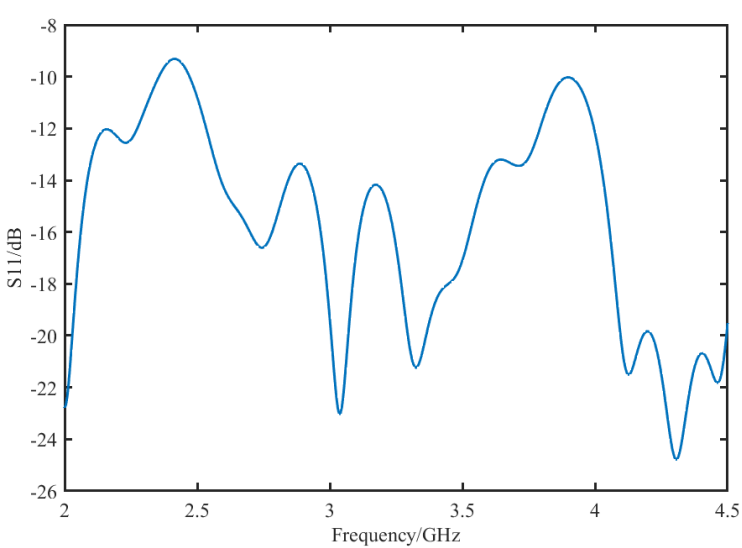

(a)

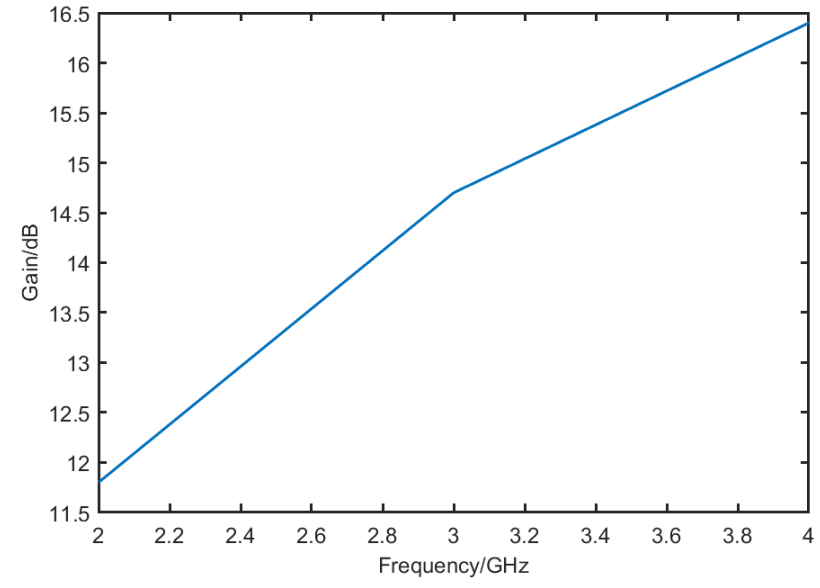

(b)

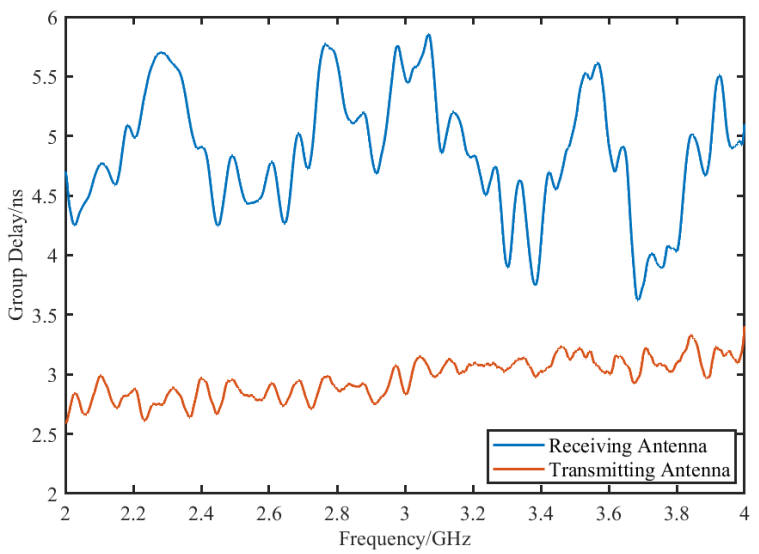

(c)

Figure 9. (a) Return loss of the simulated 8-element Vivaldi array antenna. (b) The gain of the simulated 8-element Vivaldi array antenna. (c) Group delay profile of the proposed transmitting antenna and the receiving array antenna.

\section{Verification and Discussion}

\subsection{Detection System Positioning Test}

A miniaturized and easily fabricated ultra-wideband (UWB) antenna system for long-distance electromagnetic detection is proposed. The transmitting antenna is the ultrawideband wide beam antenna discussed in Section 2.1, and the photograph is shown in Figure 10a. The receiving antenna is the ultra-wideband narrow beam eight-element array designed in Section 2.2 and the photograph is shown in Figure 10b, which was placed on a turntable support. The distance between the two antennas was fixed. During the test, the transmitting and receiving antennas were connected to two ports of the E5071C vector network analyzer (VNA) to form the Ultra-wideband Vivaldi antenna system for long-distance electromagnetic detection.

We measured the distance, $w$, between the two antennas. The VNA transmits electromagnetic wave signals through the transmitting antenna through port one. The receiving antenna has a smaller beam width. We placed it on the rotating table and connected it to port two of the VNA, and the schematic diagram of the experiment is shown in Figure 11. We observed the S21 parameter of the VNA and adjusted the angle of the rotating table to find out the azimuth angle $\theta$ of the target. We maintained the azimuth angle and then changed the VNA to time-domain. We then measured the time difference $\mathrm{T}$ from the moment when the transmitting antenna sends a signal to the moment when the receiving antenna receives the signal, and the sum distance. Then, the target position can be obtained. 


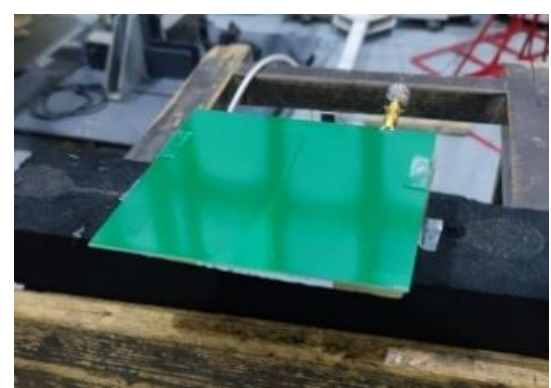

(a)

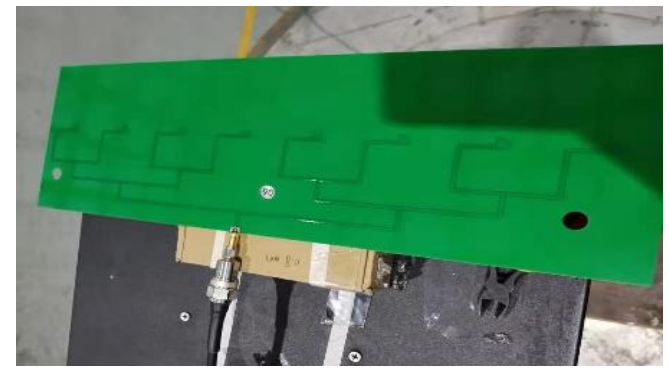

(b)

Figure 10. Photos of the proposed antennas. (a) Wide beam transmitting antenna. (b) Narrow beam receiving antenna.

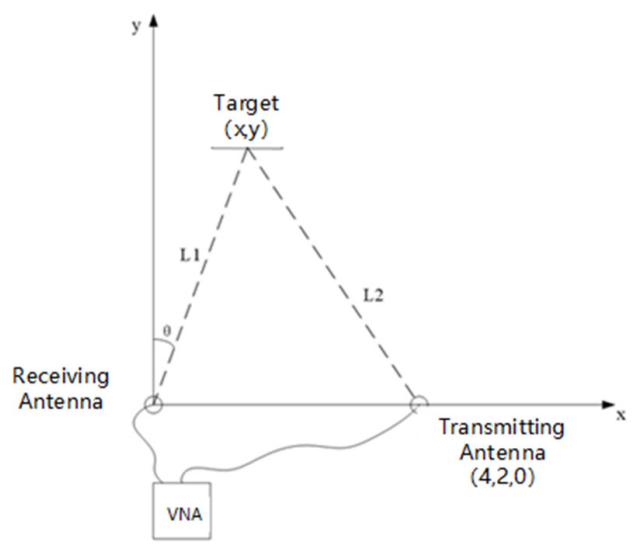

Figure 11. Experimental schematic.

\subsection{Analysis of the Test Results}

The TDT test results are shown in Figure 12. The peak point one was at $17.65 \mathrm{~ns}-5.295 \mathrm{~m}$, because two antennae were coupled. The peak point two is at $202.3 \mathrm{~ns}-60.69 \mathrm{~m}$, where the signal was reflected by the target. In Figure 11, L2 is the distance between the transmitting antenna and the target, and L2 is the distance between the receiving antenna and the target. The measured L2 was $30.31 \mathrm{~m}$, and the measured L1 was $30.2 \mathrm{~m}$ with $\mathrm{w}=4.2 \mathrm{~m}$. Undoubtedly, the measured L1 $+\mathrm{L} 2=60.51 \mathrm{~m}$. Considering the electromagnetic wave travel difference, which is determined by the difference between the cable port and the electromagnetic wave feed port, thus, the tested $\mathrm{L} 1+\mathrm{L} 2=59.6 \mathrm{~m}$.

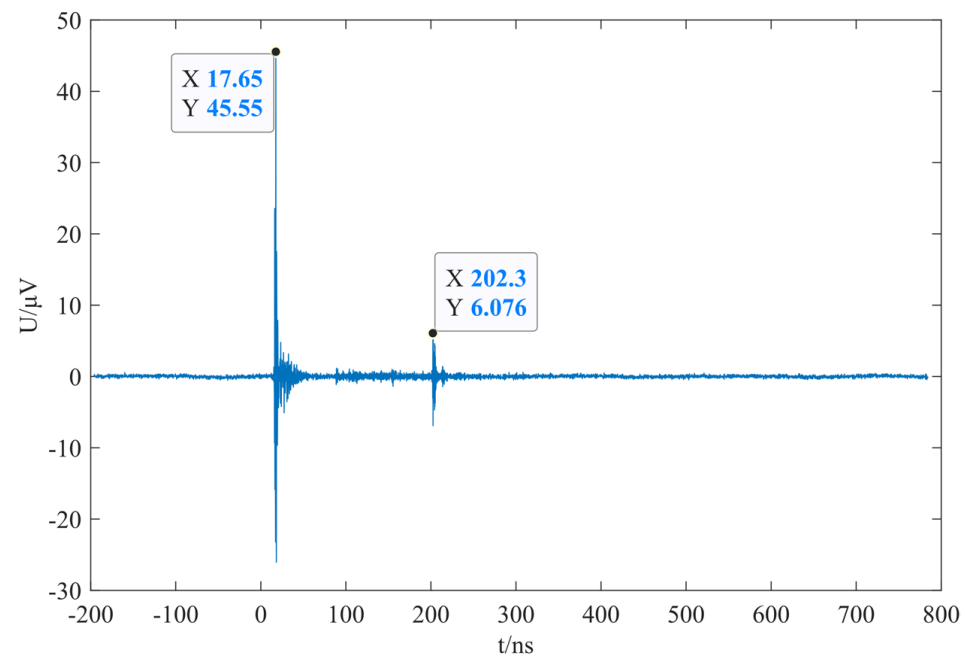

Figure 12. TDT test results. 
The actual and tested position map of the target are plotted in Figure 13. The two blue square dots at the bottom are the transmitting antenna and the receiving antenna. The coordinates $(3.278,30.13)$ is the measured target point, and $(3.138,29.86)$ is the estimated result point of the test. It can be seen from the results that the error of the coordinate values of $x$ and $y$ of this test result are both less than $0.3 \mathrm{~m}$, which meets the actual application requirements.

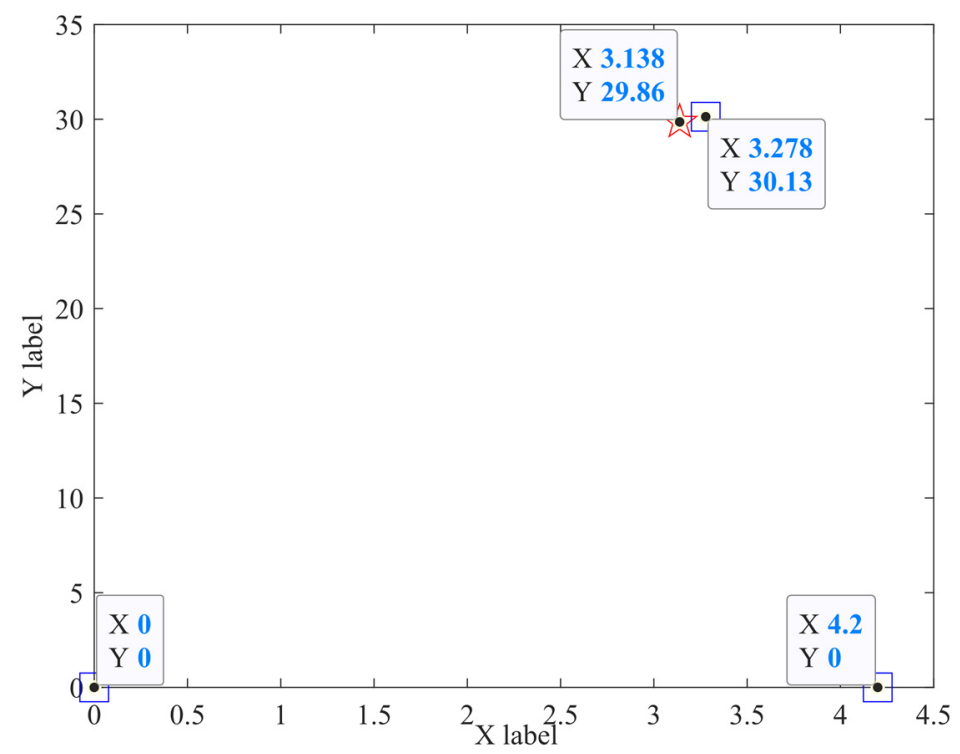

Figure 13. Actual and tested position map of the target (Unit: m).

\section{Conclusions}

In this article, an UWB Vivaldi antenna system for long-distance electromagnetic detection has been proposed. In the frequency range of $2.5 \sim 4 \mathrm{GHz}$, the transmitting antenna was an ultra-wide bandwidth beam Vivaldi antenna with HPBW above $90^{\circ}$ in the frequency range $2.5-5 \mathrm{GHz}$. The receiving antenna was an ultra-wideband narrow-beam Vivaldi antenna array. The array unit maintained HPBW less than $70^{\circ}$ in the frequency range between $2.5 \mathrm{GHz}$ and $8 \mathrm{GHz}$, and the receiving antenna was a eight-element Vivaldi array with HPBW less than $10^{\circ}$ in the frequency range of $2.5 \sim 4 \mathrm{GHz}$. It was verified by experiments that after detecting their frequency and time-domain behaviors, the detection system can achieve measurement covering a radius of $30 \mathrm{~m}$.

Author Contributions: Conceptualization, J.R.; methodology, H.F.; software, Z.Y., and J.R.; validation, Q.T., and H.F.; formal analysis, J.R.; investigation, Y.X.; data curation, J.R., H.F. and Q.T.; writingoriginal draft preparation, J.R. and Z.Y.; writing-review and editing, J.R. and X.Z.; supervision, X.Z.; project administration, Y.X.; funding acquisition, Q.T. and J.R. All authors have read and agreed to the published version of the manuscript.

Funding: This work was supported in part by the Natural Science Foundation of Jiangsu Province under Grant BK20180360, the Aero-Science Fund of China under Grant 201926069001, and the National Defence Basic Research Program of China under Grant No. JCKYS2020 DC404. And we are grateful for the assistance of the reviewers and editors.

Data Availability Statement: The data used to support the findings of this study are available from the corresponding author upon request.

Conflicts of Interest: There is no conflict of interest regarding the publication of this paper. 


\section{References}

1. Gorai, A.; Ghatak, R. Binomial stub loaded compact Vivaldi antenna for superwideband applications. Int. J. Microw. Wirel. Technol. 2020, 13, 463-468. [CrossRef]

2. Ghimire, J.; Diba, F.D.; Kim, J.-H.; Choi, D.-Y. Vivaldi Antenna Arrays Feed by Frequency-Independent Phase Shifter for High Directivity and Gain Used in Microwave Sensing and Communication Applications. Sensors 2021, 21, 6091. [CrossRef] [PubMed]

3. Li, C.; Luo, Q.; Mao, G.; Sheng, M.; Li, J. Vehicle-Mounted Base Station for Connected and Autonomous Vehicles: Opportunities and Challenges. IEEE Wirel. Commun. 2019, 26, 30-36. [CrossRef]

4. Gamec, J.; Maria Gamcova, S. Vivaldi Antenna for UWB Sensor Networks. Elektron. Ir Elektrotechnika 2016, 22, 4. [CrossRef]

5. Cicchetti, R.; Cicchetti, V.; Faraone, A.; Foged, L.; Testa, O. A Compact High-Gain Wideband Lens Vivaldi Antenna for Wireless Communications and Through-the-Wall Imaging. IEEE Trans. Antennas Propag. 2020, 69, 3177-3192. [CrossRef]

6. Reid, W.; Ortiz-Balbuena, L.; Ghadiri, A.; Moez, K. A 324-elementVivaldi antenna array for radio astronomy instrumentation IEEE Trans. Antennas Propag. 2012, 61, 241-249.

7. Hesari, S.S.; Bornemann, J. Antipodal Vivaldi Antenna Arrays Fed by Substrate Integrated Waveguide Right-Angled Power Dividers. Appl. Sci. 2018, 8, 2625. [CrossRef]

8. Wu, J.; Zhao, Z.; Nie, Z.; Liu, Q. A printed UWB Vivaldi antenna using stepped connection structure between slot line and tapered patches. IEEE Antennas Wirel. Propag. Lett. 2014, 13, 698-701. [CrossRef]

9. Dai, L.H.; Tan, C.; Zhou, Y.J. Ultrawideband Low-Profile and Miniaturized Spoof Plasmonic Vivaldi Antenna for Base Station Appl. Sci. 2020, 10, 2429. [CrossRef]

10. Ma, Z.; Wu, Q. Reduction of Mutual Coupling for Broadband Vivaldi Antennas Using Characteristic Modes Analysis and Lumped Loads. ACES J. 2019, 34, 6.

11. Yngvesson, K.S.; Korzeniowski, T.L.; Kim, Y.; Kollberg, E.L.; Johansson, J.F. The tapered slot antenna-a new integrated element for millimeter-wave applications. IEEE Trans. Microw. Theory Technol. 1989, 37, 365-374. [CrossRef]

12. Liang, T.; Xie, Y. Waveform Shaping for Maximizing the Sharpness of Receiving Voltage Waveform for an Ultra-Wideband Antenna System. IEEE Trans. Antennas Propag. 2021, 69, 5924-5930. [CrossRef]

13. Ebnabbasi, K.; Sczyslo, S.; Mohebbi, M. UWB Performance of Coplanar Tapered Slot Antennas. IEEE Antennas Wirel. Propag. Lett. 2013, 12, 749-752. [CrossRef]

14. Oraizi, H.; Jam, S. Optimum design of tapered slot antenna profile. IEEE Trans. Antennas Propag. 2003, 51, 1987-1995. [CrossRef]

15. Chio, T.-H.; Schaubert, D.H. Parameter study and design of wideband wide scan dual-polarized tapered slot antenna arrays. IEEE Trans. Antennas Propag. 2000, 48, 879-886.

16. In, D.M.; Pyo, S.; Lee, S.; Lee, M.J.; Kim, Y.S. Antipodal linearly tapered slot antenna using unequal half-circular defected sides for gain improvements. Microw. Opt. Technol. Lett. 2012, 54, 1963-1965. [CrossRef]

17. Teni, G.; Zhang, N.; Qiu, J.; Zhang, P. Research on a novel miniaturized antipodal Vivaldi antenna with improved radiation. IEEE Antennas Wirel. Propag. Lett. 2013, 12, 417-420. [CrossRef]

18. Molaei, A.; Kaboli, M.; Mirtaheri, S.A.; Abrishamian, M.S. Dielectric lens balanced antipodal Vivaldi antenna with low crosspolarisation for ultra-wideband applications. IEEE Microw. Antennas Propag. 2014, 8, 1137-1142. [CrossRef]

19. Liao, Z.; Che, Y.Z.; Luo, G.Q.; Zhang, Z.H.; Qian, Y.H.; Cai, B.G. Enhanced Radiation Characteristics for Vivaldi Antenna Using Spoof Surface Plasmon Polaritons. IEEE Trans. Plasma Sci. 2021, 49, 2730-2736. [CrossRef]

20. Shao, J.; Fang, G.; Ji, Y.; Tan, K.; Yin, H. A Novel Compact Tapered-Slot Antenna for GPR Applications. IEEE Antennas Wirel. Propag. Lett. 2013, 12, 972-975. [CrossRef]

21. Kumar Munaka, S.; Botsa, V.R.; Kumar Pukkalla, S.; Bandaru, S. In-Situ Measurements and Simulation Analysis of HIRA UWB System. In Proceedings of the 2018 15th International Conference on ElectroMagnetic Interference \& Compatibility (INCEMIC), Bengaluru, India, 13-16 November 2018; pp. 1-4.

22. Balajti, I. Performance of the VHF, "L" and "S" band radar composite signal processing. In Proceedings of the 201213 th International Radar Symposium, Warsaw, Poland, 23-25 May 2012; pp. 23-27.

23. Li, K.; Liu, M.; Zhang, H. An L-Band Ultra Wide-Band Vivaldi Antenna with Wide Beam Angle. In Proceedings of the 2020 13th UK-Europe-China Workshop on Millimeter-Waves and Terahertz Technologies (UCMMT), Tianjin, China, 29 August-1 September 2020; pp. 1-3.

24. Herzi, R.; Zairi, H.; Gharsallah, A. Reconfigurable vivaldi antenna with improved gain for UWB applications. Microw. Opt. Technol. Lett. 2015, 58, 490-494. [CrossRef]

25. Ebnabbasi, K.; Busuioc, D.; Birken, R.; Wang, M. Taper design of Vivaldi and co-planar tapered slot antenna (TSA) by Chebyshev transformer. IEEE Trans. Antennas Propag. 2012, 60, 2252-2259. [CrossRef]

26. Liu, Y.; Zhou, W.; Yang, S.; Li, W.; Li, P.; Yang, S. A Novel Miniaturized Vivaldi Antenna Using Tapered Slot Edge With Resonant Cavity Structure for Ultrawideband Applications. IEEE Antennas Wirel. Propag. Lett. 2016, 15, 1881-1884. [CrossRef]

27. Siddiqui, J.Y.; Antar, Y.M.M.; Freundorfer, A.P.; Smith, E.C.; Morin, G.A.; Thayaparan, T. Design of an Ultrawideband Antipodal Tapered Slot Antenna Using Elliptical Strip Conductors. IEEE Antennas Wirel. Propag. Lett. 2011, 10, 251-254. [CrossRef]

28. Qi, H.; Liu, H. Single-Ended Band-Notched Vivaldi Antenna With Common Mode Suppression and Low Cross Polarization. IEEE Antennas Wirel. Propag. Lett. 2021, 20, 1983-1987. [CrossRef] 